\title{
Presence of malice: Scientific evaluation of reader response to innuendo
}

\author{
THOMAS H. KRAMER, ROBERT BUCKHOUT, PAUL EUGENIO, and RORRI COHEN \\ Brooklyn College, City University of New York, Brooklyn, New York
}

\begin{abstract}
A survey was conducted to test whether or not the label "mouthpiece," which appeared in the headline "Sinatra's Mouthpiece," was viewed as a derogatory term by a representative sample of financial publication readers who saw it used in reference to a lawyer. Four matched groups of subjects rated the person described by four headlines that varied the label ("mouthpiece" vs. "spokesman") and the employer (Sinatra vs. John Doe) in a $2 \times 2$ ANOVA design. Results showed that the label "mouthpiece" produced a significantly negative impression regardless of the employer $(p<.0001)$. The data were presented in a Federal Court lawsuit that produced a ruling more in favor of the First Amendment to the Constitution than toward either litigant.
\end{abstract}

Asch (1946) contributed a set of studies in person perception that became a classic and served as a guide to the present research. Asch found that labels such as "warm" versus "cold" had a polarizing effect on subsequent trait evaluation by people who were exposed to either word in a description. The label "cold" in the description of a person polarized subsequent ratings to the more negative side, whereas the label "warm" led to more positive evaluations. In 1982, we were given the opportunity to test the generalizability of this classic finding in the context of a legal dispute centered on libel law. The issue before the court was an argument over the use of the label "mouthpiece"' as a description of a lawyer.

"Mouthpiece" was used by Barron's Business and Financial Weekly magazine in headlining a letter to the editor. The writer of the letter, Milton Rudin, was responding to an earlier Barron's article that referred disparagingly to an investment made by himself, entertainer Frank Sinatra, and others. In accordance with Mr. Rudin's request, his letter was published in "Barron's Mailbag," a column that presents letters to the editor. The point of contention in a subsequent libel suit brought by Mr. Rudin was the caption "Sinatra's Mouthpiece" printed in large type above the letter. Mr. Rudin, who is Mr. Sinatra's attorney, as well as a renowned entertainment lawyer, deemed this headline to be defamatory in that it impugned both his professional integrity and his competence as an attorney. He therefore filed suit against Dow Jones \& Company, Inc., the parent company of Barron's charging them with libel. Barron's contended, in a retraction, that the dictionary definition of "mouthpiece" is "spokesman," and therefore that "mouthpiece" cannot be construed as a defamatory term. Barron's did not, however, mention that "mouthpiece" is also defined as "a lawyer

Reprint requests should be addressed to Robert Buckhout, Center for Responsive Psychology, Brooklyn College, Brooklyn, NY 11210. who defends criminals" (Websters New World Dictionary, 1974).

We were asked by attorney Kenneth Warner, representing the plaintiff, to assist him in measuring what impact the label "mouthpiece" would have on the typical reader of financial news media when compared with a less pejorative term (e.g., "spokesman"). Implicit in this research was the possibility that the negative impressions created by the label "mouthpiece" would be confounded with the reputation of Mr. Rudin's employer, namely, Mr. Frank Sinatra. These facts suggested a natural $2 \times 2$ ANOVA design manipulating the offending label as the first variable and the name of the employer as the second variable.

The problem was to empirically determine whether use of the term "mouthpiece" generated enough negative opinion in a representative sample of business magazine readers to satisfy the legal criterion of "actionable libel."1 On this basis, a study was designed in which a sample group of older workers in the financial district in New York would be questioned about their reactions to a headline containing the label "mouthpiece" versus the label "spokesman," with either Mr. Sinatra or John Doe as the employer, to see if these headlines would produce a differential effect on a series of relevant bipolar scales having to do with a lawyer's reputation.

As this case made its deliberate way to the U.S. Federal District Court, we learned that Dow Jones \& Company (the defendant) had hired Professor Douglas Herrmann (Hamilton College, Clinton, New York) to conduct a survey of the actual readership of Barron's magazine. Unlike our matched-group design, the Herrmann (1982) study was a within-subject design measuring attitudes toward a large number of labels ("mouthpiece," "spokesman," "shyster," etc.) and employers (Sinatra, the Pope, Charlie Manson, etc.) varying in degrees of notoriety. Thus, the stage was set for adversarial presentations of empirical data in court as the suit was heard in the U.S. Federal District Courth of the Southern District of New York before the Honorable Morris Lasker. 


\section{METHOD}

\section{Subjects}

Two hundred sixty-one people were surveyed, 173 of whom were selected to match the age and occupation demographics of Barron's readership. A general profile of the readers showed that the largest age group was older ( $43 \%$ over the age of 55 years) and that $91 \%$ were employed in professional, financial, or management positions.

\section{Procedure}

The subjects were approached during lunchtime near newsstands in the financial district of New York City and were asked to respond to one of four different surveys, assigned randomly. The body of the survey sheet read as follows: "We would like to ask your cooperation as a newspaper reader. Imagine seeing the following headline printed over a letter to the editor of a paper." This was followed by on of four headlines (shown below), centered on the page and printed in large type:

\section{SINATRA'S MOUTHPIECE SINATRA'S SPOKESMAN JOHN DOE'S MOUTHPIECE JOHN DOE'S SPOKESMAN}

The instructions to the subjects continued, "Without even reading the letter, what would be your impression of the person described as a MOUTHPIECE (SPOKESMAN)? We will tell you that he is male and that he is an attorney. Please use the following checklist to give your first impression of the man called a MOUTHPIECE (SPOKESMAN) in the headline." Below these instructions were five 7-point bipolar adjectival scales (Osgood, Suci, \& Tannenbaum, 1957), which made up the dependent variables. The scales were: just . . . unjust, clean . . . dirty, ethical . . . unethical, advisor . . . puppet, and honest . . . crooked. Finally, the subjects were asked their age, sex, race, and occupation.

\section{RESULTS}

Separate $2 \times 2$ ANOVAs computed on each of the five bipolar scales produced a significant effect for the "mouthpiece" versus the "spokesman" label on each scale $(\mathrm{p}<.01)$ and nonsignificant effects for both the employer variable and the interaction. In each case,

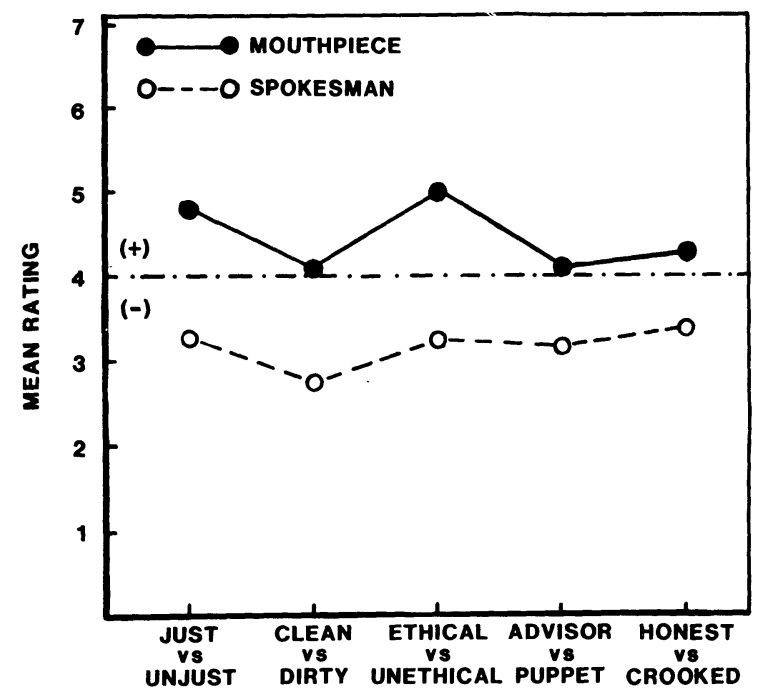

Figure 1. Comparison of mean ratings on adjectival scales averaged over subjects exposed to the "mouthpiece" headlines and the "spokesman" headlines. "mouthpiece" produced significantly more negative ratings on all five scales (see Figure 1). On each scale, "mouthpiece" was rated negative, whereas "spokesman" consistently rated on the positive end of the scale. The greatest difference (1.76) occurred on the ethical ... unethical scale $(p>.0001)$, and the least difference $(.63)$ showed on the advisor ... puppet scale $(p>.05)$. An overall $2 \times 2 \times 5$ ANOVA, treating the five scales as within-group data, was computed and yielded a highly significant main effect for label $(p<.0001)$ and a confirming significant scales $\times$ label interaction term $[\mathrm{F}(4,676)=$ $5.32, \mathrm{p}<.0003]$.

\section{DISCUSSION}

The results indicate that on all five adjectival scales, the label "mouthpiece" produced more of a negative impression of the lawyer referred to in the headline than did the label "spokesman." Earlier, pilot studies with college students had pointed to the fact that there appeared to be an age difference in how the label "mouthpiece" was perceived. Younger students related "mouthpiece" to musical instruments, part of a boxer's headgear, etc., as well as to "spokesman." It was the older students who uniformly thought of "a gangster's lawyer" as the definition. These were the respondents who gave the best indication of the Barron's readers' response. Barron's readership, being predominantly older, would have had a greater likelihood of having been exposed to the negative use of the label "mouthpiece" from older films and media coverage.

The lack of an effect of the employer (Sinatra vs. John Doe) variable and the lack of any interaction was an unexpected outcome. During the polling, there were numerous comments about $\mathrm{Mr}$. Sinatra and a surprisingly high incidence of people offering tales and anecdotes of either knowing or having met Mr. Sinatra personally. Yet, even with the celebrity status and notoriety of Mr. Sinatra, the responses on the dependent variables were not significantly different from those for John Doe. The major portion of the variance was accounted for by the "mouthpiece""spokesman" variable and not by any recognition of Mr. Sinatra.

Herrmann (1982) asked a random sample of Barron's readership for an evaluation rating of 10 occupations (including "mouthpiece" and "spokesman") on a 7-point (extremely negative to extremely positive) scale. The results showed a mean rating difference of -1.93 , with "mouthpiece" being rated within the negative range (2.57) and "spokesman" being rated on the positive side of the scale (4.50). Within this gap between "mouthpiece" and "spokesman" fell the ratings of four other occupations. Herrmann also asked readers, "Which person listed below has appeared in Barron's magazine?"'; Milton A. Rudin was one of four choices. From those who responded, $50 \%$ chose Rudin, indicating a high rate of recognition of the plaintiff.

Asch (1946) asserted that the changing of one word of a description of a person could create a qualitative change in the overall impression formed about that person and that one quality could function alone as wholly representative of the entire person. Asch contended that "once the content of a quality is determined, the evaluation of it may no longer be shifted at will, and that qualities such as warmth, bravery and humor are evaluated in a substantially constant way" (p. 15). The above results indicate that the contents of the labels "mouthpiece" and "spokesman" are clearly anchored in very different attitude domains. The substitution of one of these words for the other clearly changes the impression formed about the person it is being used to describe.

The instrument that is used to deliver a message may lend its reputation to substantiate the message (Aronson, Turner, \& Carlsmith, 1963; Schweitzer \& Ginsburg, 1966; Smith, 1973). Therefore, the fact that the derogatory term appeared in Barron's, which is perceived by its readers as a credible, trustworthy, and expert source, may have increased the negative first impression that a word such as "mouthpiece" can produce about a lawyer. Weiss (1957) showed that if the communication is from a source that has an orientation similar to that of the audience, the message will be more persuasive. 
The presentation of the above evidence and analysis at the trial by the second author was used by the plaintiff's attorney to support his client's claim that he had been libeled by Barron's use of the "mouthpiece" label. The opinion given was that the data support the conclusion that the label "mouthpiece" would produce, in the typical reader of Barron's, a negative and unflattering first impression of the person to whom it referred. A critique of Professor Herrmann's research was presented; in essence, it stated that his data from 134 actual Barron's readers confirmed our findings. In his within-group design, Herrmann found a significant difference only on the ethical ... unethical scale used to rate "mouthpiece" versus "spokesman." In his testimony for the defendant, Herrmann further argued that the name of the employer made a difference, since the data showed that the difference between "mouthpiece" and "spokesman" was narrowed when Sinatra was named as the employer.

Cross-examination of both expert witnesses, Professors Buckhout and Herrmann, was vigorous. The Dow Jones attorney pointed out trends in our data that appeared to him to indicate an employer effect despite the absence of a significant interaction term in the ANOVA. Crossexamination by the plaintiff's attorney criticized Herrman's reliance on the within-subject design and on his reliance in his testimony on pilot study results obtained from undergraduates.

In the end, it was Judge Lasker (1983) who had the last word. In his written opinion, Judge Lasker found the research presentations to be "intriguing" but to provide "ambiguous evidence at best on the question whether Barron's readers were likely to have perceived the disputed caption as a defamatory reference to Rudin (the plaintiff)"' (p. 15). Although agreeing that the evidence supported the conclusion that "mouthpiece" was clearly a more negative term than "spokesman," Judge Lasker weighed all of the evidence presented and observed that "in view of Rudin's distinguished record . . . and the respect that he commands in the legal profession as witnessed by the eminent attorneys who testified in his behalf, Rudin's reputation in the legal profession is plainly secure even if the caption chosen by Barron's were to be regarded as gratuitous or in poor taste"' (p. 25). Although he thought that serious questions had been raised by the parties about the interpretation of defamation laws, Judge Lasker concluded that the evidence did not support the need to address them directly.

The unspoken message that we saw expressed in the decision (which we regarded as a very ambiguous statement) was that Judge Lasker did not wish to open up a can of worms regarding the First Amendment to the Constitution when he did not see any serious injury to the plaintiff. In the end, the court ruled in favor of the defendant and dismissed the complaint. In the opinion of some legal observers, a door was opened to the presentation of scientific survey and psycholinguistic evidence as a basis for contesting civil suits that deal with defamation, libel, or fraudulent advertising. On reflection, we as psychologists learned a great deal about the kind of applied information needed by the court, and we welcome feedback on how best to tailor that information to the court's needs.

\section{REFERENCES}

Aronson, E., Turner, J., \& Carlsmith, J. (1963). Communicator credibility and communication discrepancy as determinants of opinion change. Journal of Abnormal and Social Psychology, 67, 31-36.

AscH, S. E. (1946). Forming impressions of personality. Journal of Abnormal and Social Psychology, 41, 258-290.

Herrmann, D. J. (1982). In re Milton A. Rudin v Dow Jones \& Co., "The meaning of mouthpiece" as held by readers of Barron's. Unpublished supporting document.

LASKER, M. E. (1983). Findings of fact In re Milton A. Rudin v Dow Jones \& Co., slip opinion in 79 Civ 433 (MEL) decided March 25, 1983 (E.D. N.Y., 1983).

Osgood, C. E., Suci, G. J., \& Tannenbaum, P. H. (1957). The measurement of meaning. Urbana: University of Illinois Press.

SchweITZeR, D., \& Ginsburg, G. P. (1966). Factors in communication credibility. In C. W. Blackman \& P. F. Secord (Eds.), Problems in social psychology (pp. 94-102). New York: McGraw-Hill.

SмIтн, R. G. (1973). Source credibility context effects. Speech Monographs, 40, 303-309.

Webster's New World Dictionary (2nd college ed., pp. 931). (1974). William Collins \& World Publishing Co., Inc.

WeIss, W. (1957). Opinion congruence with a negative source of one issue as a factor influencing agreement on another issue. Journal of Abnormal and Social Psychology, 54, 180-186.

\section{NOTE}

1. With respect to the substantive law of defamation, an article or comminication is actionable libel "if it tends to expose a person to hatred, contempt or aversion, or to induce an evil or unsavory opinion of him in the minds of a substantial number of the community, even though it may impute no moral turpitude to him' . . . (or) tend to disparage a person in the way of his office, profession or trade' (Lasker, 1983, p. 3).

(Manuscript received for publication July 13, 1984.) 